\title{
A Influência das Regras Eleitorais na Seleção dos Candidatos à Disputa Eleitoral Uma Análise Comparada Entre os Casos do Brasil e da Argentina ${ }^{1}$
}

\author{
Marcus Rodrigues \\ Doutorando em Ciência Política pela Universidade Federal de São Carlos (UFSCar).marcuslcr@yahoo.com.br
}

Gustavo André Aveline Müller

Doutor em Ciência Política pela Universidade Federal do Rio Grande do Sul (UFRGS).

Professor da Universidade Federal de Santa Maria (UFSM).gustavomuller2014@uol.com.br

RESUMO

O principal objetivo deste artigo é analisar, de forma comparada, a influência das regras eleitorais sobre os partidos políticos em geral, e, em particular, na seleção dos candidatos à disputa eleitoral na Argentina e no Brasil. Para tanto, recorreu-se à abordagem da política comparada juntamente com o aporte do neoinstitucionalismo da escolha racional. Inicialmente, realizou-se uma sucinta revisão acerca dos modelos de democracia, para, então, entrar no debate sobre os efeitos das regras eleitorais. Depois, foram apresentados os sistemas eleitorais de ambos os países e, logo na sequência de cada caso, analisada a influência das listas eleitorais na seleção dos candidatos à disputa eleitoral. A conclusão do artigo mostra que, embora as listas eleitorais tenham um efeito prescritivo sobre a seleção dos candidatos, sua influência deve ser relativizada, uma vez que outras variáveis devem ser dimensionadas para a escolha dos candidatos aos pleitos.

Palavras-chave: Democracia. Sistema eleitoral. Partidos políticos. Argentina. Brasil.

\section{ELECTORAL RULES' INFLUENCE ON THE CANDIDATES SELECTION IN ELECTORAL RACE: A COMPARATIVE ANALYSIS BETWEEN BRAZIL AND ARGENTINA}

ABSTRACT

The main objective of the article is to analyze, in a comparative way, the electoral rules' influence on political parties, particularly on the candidates selection in the electoral race in Argentina and Brazil. Therefore, the Comparative Politics, along with the contribution of the Neo-Institutionalism of the Rational Choice, was used. Initially, a concise review concerning democracy models was made, so then the debate regarding electoral rules' effects was focused. After that, the electoral systems of both countries were presented and, after each case, the electoral lists' influence on candidates selection in the electoral race was analyzed. The article's conclusion shows that, although the electoral lists have a prescriptive effect on the candidates selection, its influence must be put into perspective since other variables should be considered to choose the candidates to election.

Keywords: Democracy. Electoral system. Political parties. Argentina. Brazil.

SUMÁRIO

1 Introdução. 2 Modelos de Democracia. 3 Os Efeitos das Listas Eleitorais Sobre a Organização Partidária. 4 O Sistema Eleitoral Argentino: 1983-2001. 5 O Sistema Eleitoral Brasileiro. 6 Considerações Finais. 7 Referências.

Recebido em: 10/7/2016

Aceito em: $3 / 9 / 2016$

\footnotetext{
1 Artigo extraído da Dissertação de Mestrado em Ciências Sociais intitulada: "A Institucionalização dos partidos políticos na Argentina e no Brasil pós-terceira onda democratização: uma análise comparada", de autoria de Marcus Rodrigues, apresentada ao Programa de Pós-Graduação em Ciências Sociais da Universidade Federal de Santa Maria, em junho de 2015.
} 


\section{Democracia}

Humanos e

\section{Introdução}

A literatura sobre os partidos políticos sugere que eles são as instituições legítimas da prática representativa, sendo imprescindível às democracias representativas que os governados escolham seus governantes por meio de eleições livres e competitivas. Dado que o voto é uma condição primordial para a institucionalização da democracia, são os sistemas eleitorais que estabelecem a forma como os votos serão convertidos em assentos no parlamento. $A$ realização da disputa eleitoral passa, então, por regras formais que estabelecem os parâmetros para interação dos candidatos entre si e com os partidos e a sociedade, e, nesse sentido, a execução da representação democrática é pautada pelas regras eleitorais que regulam a competição entre os atores.Partindo da concepção de que as leis eleitorais estabelecem os critérios "institucionais e formais" para a eleição dos representantes legislativos, nosso objetivo neste artigo é ponderar sobre as influências dos arranjos institucionais nas relações estabelecidas entre os candidatos com os partidos e eleitores no caso do Brasil e da Argentina. Mais especificamente, procuramos entender se os efeitos decorrentes das listas eleitorais, tal como consagrados pela literatura política, se materializam na construção dos vínculos de lealdade partidária.

Lançando-se mão do suporte analítico neoinstitucionalista da escolha racional, radica-se na premissa de que as regras eleitorais exercem uma influência prescritiva no comportamento dos atores - sejam políticos, partidos ou eleitores -, em virtude do fato de que, em qualquer sistema político, as regras eleitorais apresentam uma correlação com a distribuição de incentivos e a aplicação de punições aos atores. Essa perspectiva consagra a lei como uma engenharia institucional, que estimularia a lógica da racionalidade instrumental e da ação estratégica, visando a promover ou evitar prováveis consequências.A qualidade da função representativa dos partidos está diretamente atrelada à capacidade do sistema de forjar lideranças políticas competentes; por isso, justificamos nosso interesse por saber até que ponto a formação da lealdade dos candidatos pode ser explicada pelos arranjos eleitorais que conformam cada país.

Para a consecução dos nossos objetivos, o texto foi dividido em seis seções. Além desta introdução, na próxima seção realizar-se-á uma breve revisão da literatura sobre democracia; na terceira, examinar-se-ão os efeitos esperados das regras eleitorais sobre os partidos; na quarta e quinta, apresentar-se-ão os sistemas eleitorais da Argentina e do Brasil e a influência das listas eleitorais na seleção dos candidatos e, por fim, uma seção conclusiva comparando os casos, e ainda, as referências bibliográficas empregadas no estudo.

\section{Modelos de Democracia}

Giovanni Sartori (1996) definiu com precisão os efeitos dos sistemas eleitorais sobre o sistema partidário a partir da distinção entre sistemas majoritários e proporcionais. Os sistemas majoritários possuem a característica de canalizar e condensar as preferências dos eleitores, fortalecendo candidaturas individuais, atuando como um estímulo para os grandes partidos; já os sistemas proporcionais, em casos extremos, podem contribuir para a fragmentação partidária. 
Os sistemas majoritários são do tipo "o vencedor leva tudo", com um candidato eleito por distrito; equivalem a distritos uninominais, com magnitude eleitoral igual a um, nos quais cada partido ou coligação pode lançar um único candidato às eleições. Nos sistemas proporcionais a distribuição das cadeiras do parlamento ocorre conforme a proporção de votos recebidos pelo partido (LIJPHART, 2003). Dentro desse quadro, o grau de proporcionalidade em que são distribuídos os assentos é determinado em razão de dois fatores:

[...] a fórmula eleitoral - que converte, para cada partido, votos em assentos legislativos - e a magnitude eleitoral, isto é, o número de representantes que cabe a cada distrito eleger, definido este último como a unidade territorial no interior da qual a distribuição dos votos entre os partidos é convertida em distribuição, entre os partidos, de cadeiras parlamentares, desprezando em princípio a distribuição dos votos entre os partidos em qualquer outro distrito do mesmo sistema eleitoral nacional (TAVARES, 1998, p. 123, grifos do autor).

A propósito, Tavares (1998) identifica "quatro elementos essenciais e comuns a todo sistema eleitoral: a circunscrição eleitoral, a estrutura do boletim de voto, o procedimento de votação e a fórmula eleitoral" (p. 36, grifos do autor). Diante de tal moldura institucional, vejamos a indagação levantada por Sartori (1996) sobre quem é eleito e se a votação se dá em pessoas ou listas. A questão é saber se os predicados pessoais são decisivos à eleição do candidato ou se a votação é fundamentalmente em listas, privilegiando o controle do partido.

De acordo com Sartori (1996, p. 29), "a votação em pessoas caracteriza os sistemas de distritos eleitorais com um só representante eleito pela maioria". É evidente que os candidatos ainda são membros dos partidos, porém, em distritos uninominais, o voto está associado mais à pessoa dos candidatos do que à legenda do partido.

Os sistemas proporcionais, a rigor, devem possuir distritos plurinominais, com elevada magnitude, ou, no mínimo, registrar uma magnitude média. Distritos com baixa magnitude - com no máximo cinco representantes - tendem a convergir para sistemas bipartidários (TAVARES, 1998).

\section{Os Efeitos das Listas Eleitorais Sobre a Organização Partidária}

Os sistemas eleitorais proporcionais de listas partidárias são amplamente utilizados nos países da América Latina, especialmente para definir a composição das câmaras baixas.

Por ora, concentramo-nos no "boletim de voto ou cédula eleitoral [que] constitui o quadro formal no qual se estrutura a decisão do eleitor" (TAVARES, 1998, p. 39, grifos do autor). Por meio dele, estipulam-se restrições à escolha do eleitor, bem como se estabelecem os parâmetros das "relações internas de poder entre os candidatos e o partido quanto à determinação dos resultados eleitorais finais" (p. 39). Com base na distinção proposta por Douglas W. Rae, Tavares (1998) considera dois tipos de voto: categórico e ordinal.

O voto categórico restringe a escolha do eleitor a um único partido ou candidato, ou, no máximo, permite-o optar por candidatos do mesmo partido. Esses limites excluem a possibilidade de o eleitor votar em diferentes partidos ou em candidatos que não sejam do mesmo partido.Figuram entre os tipos de votos categóricos: (i) sufrágio uninominal, no qual vence a eleição o candidato que alcançar o maior número de votos; (ii) sistemas de listas fechadas, 


\section{Democracia}

hierarquizadas e bloqueadas, em que os partidos apresentam uma lista preordenada de candidatos, cuja ordem tem de ser obedecida pelos eleitores; (iii) sistemas de listas flexíveis, isto é, fechadas e hierarquizadas, mas não bloqueadas, que permitem ao eleitor ordenar, conforme a sua preferência, os candidatos que constam na lista, ou mesmo alterar o ordenamento proposto pelo partido, porém sem introduzir candidatos novos ou de outras listas. $\mathrm{O}$ voto ordinal oferece ao eleitor a possibilidade de votar em ordem de preferência, alternativa ou cumulativamente, enquanto lhe permite escolher entre diferentes partidos e candidatos de distintos partidos ou listas (TAVARES, 1998). Para Tavares, portanto,

A forma clássica de voto ordinal é a lista aberta, que permite ao eleitor votar não apenas num único partido mas no candidato ou candidatos de sua preferência, eliminar candidatos e introduzir novos, votar em candidatos de listas partidárias diferentes (panachage) ou mesmo atribuir mais de um voto ao mesmo candidato (voto cumulativo), nos limites da lei eleitoral específica (1998, p. 40, grifos do autor).

Dessa modalidade derivam os sistemas de eleição proporcional sem listas partidárias, nos quais, conforme constata Tavares (1998), o partido é completamente desprovido da possibilidade de hierarquizar candidatos, desvirtuando para a relação direta entre candidato e eleitores.

Para Tavares (1998), nos sistemas proporcionais é possível projetar os tipos de boletim de voto numa espécie de continuum, de modo que, num extremo, estariam os sistemas em que o partido detém o controle exclusivo sobre o ordenamento dos candidatos, limitando a escolha do eleitor. É o que ocorre com as listas fechadas, hierarquizadas e bloqueadas. No outro extremo, os sistemas cujo eleitor escolhe o candidato de sua preferência. Desse segundo Tavares destaca três casos: o voto único transferível, o voto pessoal em candidato único e o voto uninominal, que, apenas de forma excepcional, como adotado pelo sistema brasileiro na eleição da Câmara dos Deputados, admite o voto na legenda partidária.

No voto único transferível o eleitor pode votar em um candidato e, simultaneamente, indicar outros, elaborando uma lista paralela, cujo excedente de votos será redistribuído, seguindo a ordem formada pela escolha do eleitor àqueles candidatos que tenham ultrapassado o cociente eleitoral, eliminando os que não o alcançaram. Nos outros dois o voto é

[...] contabilizado para a legenda, se transfere aleatoriamente a outros candidatos da mesma legenda e, admitida a coligação interpartidária em eleições proporcionais, a candidatos de outras legendas, equivale ao voto numa lista partidária virtual que constitui, entretanto, com sua ordenação, o resultado aleatório das escolhas de todos os eleitores do partido ou da coligação (TAVARES, 1998, p. 330).

Tavares, então, imediatamente conclui que: "Assim, ao fim e ao cabo, nem o eleitor nem o partido têm qualquer controle sobre o destino do voto e sobre a ordem de precedência dos candidatos nessa lista virtual, porque constituem efeitos compósitos e aleatórios" (1998, p. 330). 
Sobre os sistemas de listas, a pesquisa de Lijphart (2003) constatou que, a despeito de pequenas variações, todas as listas cumprem requisitos, como o de incumbir aos partidos a tarefa de apresentar listas de candidatos para eleições em distritos plurinominais, conceder ao eleitor o direito de votar numa lista e distribuir os assentos na proporção de votos obtidos pelos partidos.

Segundo Lijphart (2003), as listas de representação proporcional (RP), dependendo da sua confecção, podem ser abertas, parcialmente abertas ou fechadas. Na lista aberta os eleitores votam em candidatos de sua preferência, eleitos conforme o montante particular de votos obtidos. As listas parcialmente abertas possibilitam ao eleitor votar nos candidatos de sua preferência, embora os eleitos tendam a seguir a ordem apresentada nas listas partidárias. $\mathrm{Na}$ lista fechada o eleitor vota na lista preordenada, sendo eleitos os candidatos na ordem predeterminada pelos partidos. Os critérios, associados aos processos de formação de listas proporcionais, descritos por Lijphart (2003), remetem à questão aventada por Sartori (1996) sobre como o candidato é eleito.

Segundo o paradigma neoinstitucionalista da escolha racional, as regras criam incentivos e/ou coerções que moldam o comportamento dos atores. A tese-guia apregoada pela literatura é que os políticos têm como objetivo principal vencer eleições (CAREY; SHUGART, 1995). Para tanto, Ihes impõe observar as legislações eleitoral e partidária.

Focando na dimensão intrapartidária, mais especificamente como as cadeiras são alocadas dentro do partido, Klein (2007) põe em evidência estratégias alternativas para vencer eleições: os candidatos ao legislativo recorrem à "reputação pessoal" ou à "reputação partidária". Daí, desdobram-se duas concepções: "partidos fortes" ou "candidatos fortes" (p. 30). A prevalência de uma ou outra dependerá de duas variáveis relacionadas a duas perguntas: “1) Como os cidadãos votam? e 2) Como os partidos indicam seus candidatos?" (p. 30). ${ }^{2}$ Tais dimensões influenciam no modo como os vínculos entre os partidos e os políticos serão forjados. Certos sistemas eleitorais incentivam o candidato a cultivar comportamentos em prol da sua carreira pessoal, enquanto outros priorizam o partido. $O$ dilema que se apresenta aponta para "a tension between the collective electoral interests of a given political party and the individual electoral interests of the politicians who run for office under that party label" (CAREY; SHUGART, 1995, p. 418).

Assim, as táticas empregadas pelos políticos sofrem influência do sistema eleitoral, de modo que, nos sistemas de RP, o formato das listas partidárias, na definição dos candidatos eleitos, determina se elas priorizam o partido ou o eleitor na ordenação dos nomes nas listas. Procurando responder "como os cidadãos votam?" nos sistemas de RP de listas, Klein (2007, p. 30) reformula a questão e se interroga sobre "como as cadeiras conquistadas pelos partidos serão alocadas entre seus candidatos?" Nesse ponto, a configuração das listas auxilia a compreensão, uma vez que é por meio delas que se avalia o controle que as lideranças partidárias têm sobre o acesso e a posição dos candidatos nelas (CAREY; SHUGART, 2007).

\footnotetext{
2 Klein, seguindo os critérios de Carey e Shugart (1995), atenta à existência de outras duas influentes variáveis no sistema eleitoral: a magnitude distrital e "se os votos são ou não transferíveis ou agregáveis" (KLEIN, 2007).
} 


\section{Democracia}

Nos países que utilizam a RP de lista entre os principais formatos apontados pela literatura especializada, estão a lista fechada, a lista aberta, a lista flexível e a lista livre (KLEIN, 2007; TAVARES, 1994).

Na eleição em lista fechada, adotada na Argentina, a cúpula do partido controla a ordem dos candidatos nas listas, que não podem ser alteradas pelos eleitores. O voto é, prioritariamente, no partido, reforçando a cooperação e a lealdade partidária.

$\mathrm{Na}$ eleição com lista aberta, o eleitor pode votar no candidato de sua preferência, não existindo ordenação prévia de nomes. As primeiras vagas de cada lista são distribuídas entre os candidatos mais votados até preencher todas as cadeiras conquistadas pelo partido ou coligação. Tal sistema, como utilizado no Brasil, permite ao eleitor votar em candidatos ou na legenda.

Eleições com lista flexível possibilitam ao eleitor escolher um candidato ou reordenar a lista partidária, porém permitem votar em uma única lista. Nessas condições, quanto maior a votação individual obtida por um candidato maior sua chance de galgar melhores posições na lista e de se eleger.

Por fim, a eleição em lista livre, bastante similar à lista aberta, uma vez que as listas não são preordenadas pelo partido, concede liberdade de escolha ao eleitor.

Em resumo, no voto em lista fechada o partido detém o controle sobre a formatação da cédula eleitoral; nos votos em lista aberta e livre o eleitor pode escolher candidatos individuais. Simultaneamente, a literatura alega que a lista fechada reforça a centralização do partido, enquanto a lista aberta estimula campanhas individualistas. Assim, o nível de disputa intrapartidária dependerá dos incentivos gerados pelas legislações eleitoral e partidária. Logo, a relevância dos partidos na definição das listas pode ir de uma influência fraca e limitada a uma forte centralização quanto à disposição dos nomes. Tal proposição gira em torno da resposta à segunda questão levantada por Klein (2007): "Como o partido indica seus candidatos?" Argumenta que lançar candidatos às eleições pode ser uma tarefa "fácil ou difícil" conforme as legislações eleitoral e partidária, que propiciam ao partido desde a completa centralização até uma grande descentralização.Sistemas com grande centralização asseguram o controle partidário sobre a indicação dos candidatos, fazendo disso função exclusiva de uma elite. É usual em sistemas de lista fechada. Como é o partido que define a ordem dos nomes na lista, os candidatos perseguem os mesmos objetivos - ganhar votos para o partido -, o que os induz à cooperação e ao comprometimento com a legenda. Na concepção de Carey e Shugart (1995), a lista fechada privilegia candidaturas baseadas na reputação partidária ao invés da reputação pessoal.

Por outro lado, nos sistemas em que vigora o voto preferencial - seja por meio da lista aberta ou da livre - o controle partidário na indicação dos candidatos tende a ser menos centralizado, uma vez que o eleitor interfere na escolha dos candidatos eleitos. Daí, segue-se um argumento consagrado pela literatura, segundo o qual a lista aberta favorece as candidaturas individuais em prejuízo ao partido. Nesse quadro, os partidos mantêm vínculos tênues com os candidatos, que constroem sua carreira política centrada na reputação pessoal. Por conseguinte, a possibilidade de o candidato triunfar eleitoralmente caminha pari passu com a sua capacidade de desenvolver vínculos pessoais com os eleitores. 
São atribuídas constantes críticas a esse modelo, afirmando que a lista aberta acirra a competição intrapartidária, estimula o voto personalista e fragiliza a legenda, minando sua coesão interna. Afinal, para se eleger os políticos precisam angariar votos individuais; então, recorrem a campanhas personalistas, conduzidas com autonomia ante os partidos. De acordo com Carey e Shugart (1995, p. 419), as dinâmicas partidárias, estruturadas por carreiras políticas baseadas na reputação individual, são

[...] frequently associated by U.S. political scientists with legislative particularism - securing pork-barrel funding for projects that benefit specific districts, and providing errand-boy services to solve individual constituents' problems with government bureaucracy.

É preciso relativizar, contudo, a importância do formato das listas sobre a organização partidária, pois, além do próprio sistema eleitoral, outros aspectos do sistema político também afetam a sua organização. Não pretendemos explorar todas as variáveis envolvidas na organização partidária, mas, sim, avaliar a relevância das listas na construção dos vínculos intrapartidários.

Se, por um lado, há uma profusão de estudos sobre os efeitos dos sistemas eleitorais nos sistemas partidários, por outro ainda há pouco conhecimento a respeito de como o sistema eleitoral afeta a dimensão intrapartidária, isto é, como afeta a organização interna do partido e a relação dos legisladores e candidatos ao legislativo com os eleitores (SHUGART, 2005). A seguir, apresentar-se-ão os sistemas eleitorais da Argentina e do Brasil, a fim de ilustrar os principais efeitos dos diferentes tipos de listas sobre a construção das carreiras políticas, buscando observar se correspondem aos argumentos expostos.

\section{O Sistema Eleitoral Argentino: 1983-2001}

A Argentina é uma República Federativa Presidencialista, como explícito no primeiro artigo da sua Constituição: "La Nación Argentina adopta para su gobierno la forma representativa, republicana, federal [...]". ${ }^{3}$ A federação está dividida em 23 províncias (que são equivalentes aos Estados brasileiros), mais a Cidade Autônoma de Buenos Aires, que possui status de distrito federal e é a capital do país (ROJO, 1998). Destarte, a Constituição assegura-lhes autonomia administrativa. ${ }^{4}$ Investido de prerrogativas para a condução administrativa, o nível provincial de governo tem um peso decisivo na indicação dos candidatos para efeito de composição das listas.

O Poder Legislativo constitui um Congresso bicameral (Câmara dos Deputados e Senado) que se baseia nos princípios da representação populacional e territorial, sendo de competência exclusiva dos partidos apresentarem candidatos a cargos eletivos. ${ }^{5}$

\footnotetext{
Artigo 1 da Constitución de la Nación Argentina, 1994.

4 Ver: Artigos. 5, 121 e 122 da Constitución de la Nación Argentina, 1994.

Ver: Artigo 38 da Constitución de la Nación Argentina, 1994.
} 


\section{Democracia}

Humanos e

A Câmara dos Deputados compõe-se de 257 membros, $^{6}$ eleitos por distritos plurinominais - correspondentes às províncias e à Capital federal - cuja magnitude depende da proporção da população de cada distrito eleitoral -, sendo assegurados, no mínimo, 5 deputados a cada distrito. A Câmara é renovada pela metade (127 e 130 assentos) a cada dois anos, renovando-se metade - ou quase - da bancada de cada distrito. O mandato de deputado tem duração de quatro anos, com possibilidade de reeleição irrestrita. As listas de candidatos a deputados são fechadas e bloqueadas, utilizando o método D'Hondt de distribuição de cadeiras, com uma cláusula de barreira fixada em 3\% (ALCÁNTARA SÁEZ, 2003; DE LUCA; JONES; TULA, 2002; ROJO, 1998).

Como anteriormente fora argumentado, nas listas fechadas os partidos são os responsáveis pela indicação prévia dos candidatos ao pleito. Sobre o efeito provocado pelos incentivos eleitorais na construção das carreiras políticas, Jones et al. (2002, p. 657-658) observam que:

In federal countries with a closed-list PR electoral system, the process by which the provincial (district) party lists are formed largely affects which candidates run on each party list, what order they occupy, and, consequently, their chances of winning a seat in Congress. Hence, depending on the role that electoral rules give local party leaders in the creation of the district-party list, local party leaders may or not be key in the determination of legislators' futures.

A esse respeito, as considerações dos autores citados sobre o sistema eleitoral argentino apontam a província como o berço das aspirações políticas dos partidos na Argentina. Dispondo de amplos recursos, as lideranças partidárias locais têm primazia sobre a distribuição de incentivos. Isso ocorre especialmente no que respeita à nominação de candidatos, em que os líderes partidários, no âmbito provincial, controlam o processo de confecção das listas. Pelos critérios estipulados por Carey e Shugart (1995), depreende-se que o sistema eleitoral argentino restringe a autonomia dos políticos, inibindo suas pretensões de investirem na sua reputação pessoal diante da reputação partidária, o que também implica assumir que, "From the Argentine legislator's point of view, in order to pursue their desired career paths, they must maintain a good relationship with their local party bosses" (JONES et al., 2002, p. 658). Em outros termos, o sucesso na carreira política depende dos incentivos controlados pelas elites partidárias.

Endossa tal assertiva o fato de os chefes provinciais estimularem a circulação dos políticos na Câmara, inviabilizando que desenvolvam longas carreiras no Congresso. Como resultado dessa prática parlamentar, Jones et al. (2002) acusam a maioria dos legisladores argentinos de serem "legisladores amadores", embora sejam "políticos profissionais".

\section{A Estratégia Eleitoral sob a Lista Fechada}

As províncias na Argentina têm autonomia administrativa, e os governadores são considerados atores políticos com um peso decisivo. Outrossim, espera-se que as organizações partidárias, em âmbito local, desempenhem importante função na seleção de candidatos. Em

Até 1991 a Câmara dos Deputados contava com 254 legisladores, e adicionou mais 3 após a conversão da Terra do Fogo em província. 
decorrência dessa dinâmica, Jones (2008, p. 42) argumenta que: "Argentine legislators are closest to the party loyalist type. This loyalty however is to the provincial-level party, not to the national party". Assim, as lealdades são aos líderes partidários na esfera provincial, que controlam as máquinas eleitorais, essenciais à construção de redes de apoio e, não raro, são os encarregados pela formatação das listas.

Tratando da nominação de candidatos, De Luca, Jones e Tula (2002) apontam três procedimentos empregados pelas direções partidárias entre 1983 e 2001: indicação restrita às elites (os arranjos de bastidores), eleições em assembleias e eleições primárias. ${ }^{7}$ No primeiro caso existem diferentes formas de as elites facultarem o acesso dos candidatos às listas, podendo ocorrer pela imposição de uma lista por um caudilho no plano provincial - por exemplo um poderoso governador - ou as listas podem provir de negociações entre as elites partidárias das províncias. No segundo, elas surgem como produto das assembleias realizadas pelos partidos em âmbito provincial. Na última versão, duas ou mais listas são submetidas pelos partidos a eleições primárias diretas.

Segundo De Luca, Jones e Tula (2002), os critérios mais empregados pelas direções partidárias no processo de seleção dos candidatos, são as primárias com voto direto e indicação pelas elites partidárias. Pela avaliação de 610 processos de indicação de candidatos para as eleições bianuais à Câmara dos Deputados Argentina entre 1983 e 2001, os autores observam que a escolha por um ou outro procedimento dependerá tanto de aspectos institucionais quanto partidários. Assim, a hipótese arguida pelos autores estima a incidência de sete principais fatores que podem explicar a decisão de um partido em adotar primárias ou se a escolha dos candidatos é realizada por deliberação das elites.

1. "Provincial opposition party" - os autores supõem que os partidos, em âmbito distrital, nas províncias em que controlam o governo, tendem a escolher os candidatos por um arranjo elitista ao invés das primárias.

2. "Incumbent governor/reelection" - se o governador do Estado busca a reeleição, a probabilidade de o partido realizar primárias na seleção dos candidatos à Câmara é menor do que de um governador que não disputa a reeleição ou dos partidos que não controlam o governo.

3. "National governing party" - havendo concomitância entre o partido na esfera provincial e o presidente em exercício, aumenta a capacidade de indicação dos candidatos pelo presidente no plano provincial, sendo maior a probabilidade de se aplicar um arranjo elitista do que os partidos de oposição.

4. "Contagion" - caso a realização de primárias por um partido da província revele-se uma vantagem para mobilizar apoio entre o eleitorado, e tida como uma ameaça, justificar-se-ia, nesse caso, seguir o exemplo do partido rival, e, sob o mesmo pretexto, realizar primárias neutralizando a potencial vantagem da oposição.

Nos termos originais: "elite arrangement (back room), assembly election and direct primary (ballot box)" (DE LUCA; JONES; TULA, 2002). 


\section{Humanos e}

Democracia

5. "1983 election year" - durante os anos de ditadura os militares proscreveram os partidos políticos, acarretando num resfriamento da atividade política. Com o fim do interregno democrático, em 1982 os partidos voltam a se organizar para as eleições de 1983. Em pouco tempo - menos de um ano - foi preciso otimizar recursos para as eleições; por isso, para os autores, seria plausível supor que o tempo exíguo encorajou o emprego de arranjos elitistas no lugar de primárias.

6. "UCR in Alianza" - a Aliança formada entre UCR e Frepaso apresentou uma única lista de candidatos para a Câmara em 14 províncias nas eleições de 1997, em 23 nas de 1999, e em 16 no pleito de 2001. Tal coligação significou uma experiência inédita no país, entre 1983 e 2001, de uma aliança selada entre dois partidos de expressão nacional e com peso político relativamente semelhante. Dada a necessidade de negociação entre os partidos sobre a posição dos candidatos nas listas, os autores partem do pressuposto de que os partidos tendem a evitar primárias para reduzir as incertezas na escolha dos candidatos ao Legislativo.

7. "PJ, UCR, minor national party, provincial party, MPN-MPF (Movimiento Popular Nequino-Movimiento Popular Fueguino)" - estas cinco variáveis são ponderadas com o objetivo de examinar os efeitos previstos pelos partidos. Para isso, os autores formulam as seguintes hipóteses: 1) em razão das diferenças estruturais de organização e liderança, eles esperam que o partido, em âmbito provincial, tenha um efeito inverso no que diz respeito à probabilidade de realizar primárias; 2 ) os autores esperam que a UCR tenha maior propensão de realizar primárias do que o PJ, que possui uma estrutura política tradicionalmente vertical e pouco institucionalizada.

Como resultados das suas análises, foram extraídas quatro lições condizentes à decisão dos partidos quanto a escolher seus candidatos por meio de primárias em vez de adotar arranjos elitistas:

First, parties in the opposition are more likely to hold primaries than parties in government. Second, among parties in government, instances in which the executive cannot stand for immediate reelection are likely to lead to a greater use of primaries than those in which the incumbent can run for reelection. Third, the establishment of stable alliances between two relatively equal partners is likely to reduce the probability that legislative candidates will be chosen via primaries. Fourth, the smaller the size of a party's membership and extent of its institutional presence and the larger the degree to which it is dominated by a single person or small clique, the lower the probability that it will hold primaries to choose its candidates for public office (DE LUCA; JONES; TULA, 2002., p. 432-433).

Seguindo a análise dos autores, concluímos que as elites provinciais, sobretudo aquelas que se encontram no comando de cargos executivos importantes, detêm grande influência, senão o controle, sobre a confecção das listas partidárias.

\section{Sistema Eleitoral Brasileiro}

A Constituição Federal (CF) de 1988 prevê a realização de eleições diretas para os cargos do Executivo e Legislativo, mediante o voto universal, direto, secreto e obrigatório para os maiores de 18 anos e facultativo para os analfabetos, os maiores de 70 anos e os com idade entre 16 e 18 anos (artigo 14 CF/88). O primeiro artigo da CF estabelece a organização do Es- 
tado brasileiro como uma República Federativa, formada pela união dos Estados, municípios e Distrito Federal. A Federação brasileira é composta por 27 entes federados, divididos em 26 Estados e 1 Distrito Federal.Ao Congresso Nacional incumbe o Poder Legislativo, com uma estrutura bicameral formada pela Câmara e Senado. Os Estados correspondem às circunscrições eleitorais para a eleição dos membros de ambas as Casas Legislativas. As eleições para presidente da República, governadores, deputados federais, estaduais e senadores ocorrem simultaneamente.

A Câmara dos Deputados tem como princípio a representação da população, constituindo-se de 513 deputados, eleitos proporcionalmente com relação à população de cada Estado, observando o limite mínimo de 8 e máximo de 70. Os deputados são eleitos pelo sistema de representação proporcional com voto preferencial em distritos plurinominais. A alocação das cadeiras na Câmara é calculada pela fórmula D’Hondt para conversão de votos em mandatos, com uma cláusula de barreira estipulada conforme o cociente eleitoral de cada unidade estadual (NICOLAU; SCHMITT, 1995).

Para nossos fins, uma questão a saber é até que ponto os partidos condicionam a escoIha dos eleitores. No voto preferencial, os eleitores podem votar em candidatos específicos. Nesses casos, a literatura indica que os eleitores estão mais propensos a apoiar candidatos individuais em detrimento aos partidos, valorizando vínculos personalistas. Em síntese, sabe-se que, no sistema de lista aberta brasileiro, prevalecem: a) campanhas eleitorais centradas nos candidatos; b) a escolha dos eleitores na eleição dos candidatos ante ao reduzido controle partidário (NICOLAU; SCHMITT, 1995).

Mainwaring (1991) acusa a combinação de representação proporcional com lista aberta como um dos principais fatores responsáveis pela autonomia dos políticos em relação aos partidos.

A representação proporcional de lista aberta foi, pela primeira vez, consagrada pelo Código Eleitoral de 1932, e, desde 1945, segue sendo utilizada para a escolha dos deputados federais. Isso torna o Brasil o país que, há mais tempo, emprega o modelo de votação preferencial, no qual é dada aos eleitores a opção de votar em candidatos de sua preferência (GIUDICE, 2010; NICOLAU, 2006b). Segundo Nicolau e Schmitt (1995, p. 143),

O mecanismo de funcionamento da lista aberta no Brasil é muito simples: o eleitor tem duas escolhas, ou vota em um partido (voto de legenda), ou em um candidato (voto nominal). A votação total de um partido - que será usada para a alocação de cadeiras - é o resultado da soma dos votos dados à legenda mais os votos nominais. Diferentemente da maioria das democracias que empregam a representação proporcional de lista, não há no sistema de voto preferencial brasileiro nenhum tipo de ordenamento dos nomes da lista antes das eleições, nem qualquer forma de favorecimentos para candidatos específicos da lista.

É frequentemente atribuída à lista aberta a responsabilidade por efeitos deletérios sobre os partidos brasileiros. Um ilustre interlocutor dessa concepção é Mainwaring (1991), para quem os resultados produzidos por esse sistema privilegiam estratégias individuais e exacerbam a competição intrapartidária. Mainwaring (1991, p. 42) advoga que "Nenhuma democracia do mundo ocidental dá aos políticos tanta autonomia em relação a seus partidos quanto o Brasil". 


\section{Democracia}

Humanos e

Para ele, essa autonomia inicia-se na projeção de campanhas eleitorais excessivamente individualistas. Como consequência do individualismo nas campanhas eleitorais, "prevalece uma acirrada competição entre as pessoas que concorrem a cargos proporcionais (por exemplo, entre candidatos a deputado federal)" (1991, p. 43). Diante disso, Mainwaring sustenta que, "Entre os partidos sempre-cabe-mais-um, a competição intrapartidária é frequentemente - e talvez até usualmente - mais acirrada do que a competição interpartidária" (1991, p. 43).

Outro aspecto da legislação eleitoral, frisado por Mainwaring, é que ela "estimula a autonomia dos representantes eleitos em relação a seus partidos" (1991, p. 44). Pesa, para isso, o fato de que "eles não devem seus mandatos ao partido, mas sim à sua própria iniciativa. Os partidos aceitam violações flagrantes dos programas partidários e dos compromissos organizacionais quando um político consegue uma grande soma de votos" (1991, p. 44).

Sendo assim, a baixa identificação partidária, aliada a uma legislação eleitoral excessivamente permissiva, contribuiria para que os políticos brasileiros se comportassem de modo individualista e antipartidário.

Nem todos os analistas, todavia, foram condescendentes com o ponto de vista de Mainwaring. Como se sabe, há uma carência de estudos sobre as estratégias empregadas pelos partidos na composição das listas, sobretudo como são selecionados os candidatos concorrentes às eleições proporcionais (FIGUEIREDO; LIMONGI, 2002; NICOLAU, 2006a). Conforme observou Nicolau (2006a), a pesquisa de Mainwaring (1991) carece de evidências empíricas. Em seu rastro, Figueiredo e Limongi (2002) questionam o suposto diagnóstico apresentado por Mainwaring (1991), de que a lista aberta estimula a disputa intrapartidária, relegando a um plano secundário o partido. Explicam que os candidatos continuam beneficiados com a votação nos companheiros de chapa, pois, sendo os votos transferíveis, aumentam suas chances de eleição com os votos dados ao partido ou coligação. Outro exemplo são os candidatos que obtiveram votação expressiva, porém não se elegeram porque seu partido não atingiu o cociente eleitoral. Então, no "sistema de 'lista aberta', a competição intrapartidária não suplanta a interpartidária" (2002, p. 309). Tampouco os partidos seriam desprovidos de controle interno; pelo contrário, a análise de Braga (2008) demonstra que, mesmo em graus diferenciados, os partidos controlam o processo de seleção de candidatos e a oportunidade de acesso à lista partidária, o que, no mais, garantiria aos partidos uma maior capacidade de reduzir a incerteza quanto aos resultados eleitorais

\section{A Estratégia Eleitoral sob a Lista Aberta}

Nicolau (2006a) argumenta que um conjunto de fatores influenciará na quantidade e no perfil dos candidatos lançados pelos partidos em cada circunscrição, tais como o seu tamanho, a possibilidade de estabelecer coalizões e o número de competidores. Considera, então, a hipótese de que "tanto a dimensão territorial como a diversidade social dos candidatos são fatores fundamentais para os organizadores da lista" (p. 695). Seguindo esses parâmetros, os responsáveis por preparar as listas levariam em conta a dimensão geográfica, recrutando candidatos em distintas áreas do Estado, procurando não sobrepor nomes dentro de uma mesma região, no que, ainda, buscariam pessoas ilustres, com prestígio junto a setores do eleitorado, líderes sindicais, líderes religiosos, ativistas de movimentos sociais ou pessoas que tenham se notabilizado em algum ramo específico de atuação. Nicolau (2006a) ressalva, entretanto, que 
apenas com estudos mais detalhados sobre o perfil dos candidatos, poderá se confirmar a importância desses critérios. Ademais, dois aspectos merecem especial menção: “O primeiro é que nenhum partido utiliza prévias internas com os filiados para a escolha dos nomes que comporão a lista, o segundo é que as convenções oficiais têm caráter meramente homologatório, já que os candidatos são escolhidos antes que elas aconteçam" (p. 695).

Por fim, pode-se afirmar que a lista aberta, sob a ótica de Klein (2007) e Figueiredo e Limongi (2002), fornece uma versão mais "otimista" do que a descrita por Mainwaring (991). Destarte, atribuem ao partido uma função essencial no processo de elaboração das listas partidárias. "A importância da composição da lista, uma prerrogativa da convenção partidária, não deve ser desconsiderada" (FIGUEIREDO; LIMONGI, 2002, p. 310).

Um ponto, entretanto, parece ser unanimidade: o alto custo financeiro das campanhas. Segundo Klein (2007), contribuiria para isso a incerteza gerada pelo sistema de lista aberta. "Como os candidatos são os principais responsáveis pela arrecadação de recursos para a candidatura e precisam se diferenciar de centenas de outros, eles seriam levados a despender mais dinheiro na tentativa de diminuir a incerteza de sua eleição" (p. 67).

Nicolau (2006a) chama atenção para a autonomia dos candidatos na organização das campanhas. Cabe a cada um organizar sua campanha, sendo o responsável pela definição da sua agenda de eventos, criação de comitês, arrecadação de recursos, gastos com propaganda e confecção de material. "Os candidatos podem arrecadar, gastar e prestar contas diretamente à Justiça Eleitoral, sem necessidade de o partido avalizar os gastos" (p. 696).Dessa forma, a estratégia adotada pelo candidato vai depender, principalmente, do seu perfil político e da quantidade de recursos disponíveis, embora pareça comum a todos buscar o contato pessoal com os eleitores, seja por meio da realização de comícios, atividades públicas ou reuniões com grupos de interesse. Em tese, nos sistemas proporcionais os candidatos tendem a realizar suas campanhas visando a setores específicos do eleitorado, dado que necessitam obter apenas uma fração de votos para se elegerem.Tratando das estratégias utilizadas pelos candidatos no sistema proporcional de lista aberta brasileiro, Barry Ames (1995) elaborou a mais famosa taxonomia da geografia eleitoral. Ele reconhece que, embora os candidatos possam buscar votos em todos os municípios do Estado, a maioria tende a limitar geograficamente suas campanhas. Para tanto, Ames identifica quatro padrões espaciais de distribuição dos votos dos candidatos à Câmara dos Deputados: 1) concentrado-dominante: é o clássico reduto eleitoral, onde o candidato recebe alta porcentagem dos votos concentrada em um conjunto de municípios contíguos; 2) concentrado-compartilhado: quando a proporção de votos dados a um candidato está, em boa medida, concentrada em uma determinada área cujo eleitorado é compartilhado com outros concorrentes. Ocorre em regiões metropolitanas (com distritos eleitorais de alta magnitude), onde uma fatia do enorme eleitorado é suficiente para eleger vários candidatos; 3 ) disperso-compartilhado: nesse caso, o candidato busca amealhar votos oriundos de pequenos segmentos do eleitorado disperso entre vários municípios, sem dominar qualquer região. Geralmente, conta com o apoio de grupos coesos, por exemplo os nipo-brasileiros ou os evangélicos; 4) disperso-dominante: é o caso de candidatos que recebem votações massivas em diversos municípios; típico de candidatos que estabelecem acordos com líderes locais ou que exerceram cargos na administração pública. 


\section{Democracia}

Humanos e

A taxonomia desenvolvida por Ames (1995) mostra distintas estratégias empregadas pelos candidatos ao Legislativo, e, por conta disso, os custos das campanhas variam de acordo com cada candidato.

\section{Considerações Finais}

Pela análise da seleção dos candidatos, pôde-se verificar que os efeitos atribuídos às listas eleitorais não se concretizam, nos casos do Brasil e da Argentina, exatamente como concebido pela literatura. Segundo informa parte da literatura, vimos que os incentivos gerados pelas listas aberta e fechada levam os candidatos a recorrerem, respectivamente, à reputação pessoal ou partidária.Na Argentina, onde vigora a lista fechada, embora haja a realização de eleições primárias para nominação de candidatos, prevalecem os acordos entre as elites partidárias na confecção das listas. Geralmente os líderes provinciais dos partidos são os principais responsáveis pela preparação das listas de candidatos à Câmara Nacional.

Tais lideranças controlam recursos estratégicos para a sustentação das carreiras políticas, o que lhes assegura grande influência sobre os políticos. Prova disso é a rotatividade que os líderes provinciais infligem aos parlamentares, acarretando uma baixa continuidade nas carreiras políticas. Em linhas gerais, os políticos que aspiram ao sucesso na carreira dependem dos recursos de que dispõem os líderes distritais; portanto, as lealdades partidárias são sedimentadas em âmbito provincial. Assim, em divergência à literatura que esperaria uma lealdade partidária orientada nacionalmente, no caso argentino, a lealdade é em escala subnacional, fortalecendo os grupos locais em detrimento das instâncias nacionais dos partidos.

No caso do Brasil, as consequências deduzidas do modelo de lista aberta gerariam incentivos à reputação pessoal, conforme as teses previstas pelos autores brasilianistas. Na crítica desses analistas, as regras eleitorais - mormente à representação proporcional de lista aberta - contribuiriam para a debilidade dos partidos, estimulando a promoção de campanhas personalistas, vínculos tênues entre os políticos e partidos, acirrada competição intrapartidária exacerbando a autonomia dos políticos ante os partidos. Vimos, então, que essa não é uma interpretação inequívoca. Há um consenso entre outros cientistas políticos sobre a dificuldade de mensurar a personalização do voto. Em contrapartida, rebatem o diagnóstico caótico retratado por aquela corrente, argumentando, entre outras coisas, que, como os votos são transferíveis, todos os candidatos são beneficiados com os votos na legenda, uma vez que aumentam suas chances de eleição e, assim, produzir-se-iam estímulos estruturais à cooperação partidária. De mais a mais, apesar da tese de que a lista aberta reforça a autonomia dos candidatos, as prerrogativas partidárias, na formação da lista de candidatos, não devem ser subestimadas. De qualquer modo, é bom frisar que o formato das listas eleitorais, por si só, tem um efeito limitado sobre a seleção das candidaturas, afinal influem, também, outros aspectos, como o tamanho dos distritos eleitorais, a estrutura federal de governo e a dinâmica interna dos próprios partidos além de regras e procedimentos formais e informais.

\section{Referências}

ALCÁNTARA SÁEZ, Manuel. Sistemas políticos de América Latina. Madri: Tecnos, 2003. V. I.

AMES, Barry. Electoral Strategy under Open-List Proportional Representation. American Journal of Political Science, v. 39, n. 2, p. 406-433, 1995. 
ARGENTINA. Constitución de la Nación Argentina, 1994. Disponível em: <http://www.senado.gov.ar/>.

BRAGA, Maria do Socorro Sousa. Organizações partidárias e seleção de candidatos no Estado de São Paulo. Opinião Pública, Campinas, vol. 14, n. 2, p. 454-485, nov. 2008.

BRASIL. Constituição da República Federativa do Brasil de 1988. 35. ed. São Paulo: Saraiva, 2005.

DE LUCA, Miguel; JONES, Mark P.; TULA, Maria Inés. Back Rooms or Ballot Box? Candidate Nomination in Argentina. Comparative Political Studies, v. 35, n. 4, p. 413-436, 2002.

CAREY, John; SHUGART, Matthew. Incentives to cultivate a personal vote: A rank ordering of electoral formulas. Electoral Studies, v. 14, n. 4, p. 417-439, 1995.

FIGUEIREDO, Argelina C.; LIMONGI, Fernando. Incentivos eleitorais, partidos e política orçamentária. Dados, Rio de Janeiro, v. 45, n. 2, p. 303-344, 2002.

GIUDICE, Noelle D. O sistema proporcional no Brasil: origens, características e efeitos. Em Debate, Belo Horizonte, v. 2, n. 7, p. 21-28, 2010. Disponível em: <http://www.opiniaopublica.ufmg.br/emdebate/noelle11.pdf>. Acesso em: jun. 2014.

JONES, Mark P. et al. Amateur Legislators, Professional Politicians: The Consequences of Party-Centered Electoral Rules in Federal Systems. American Journal of Political Science, v. 46, n. 3, p. 656-669, 2002.

JONES, Mark. P. The Recruitment and Selection of Legislative Candidates in Argentina. In: SIAVELIS, P.; MORGENSTERN, S. (Ed.). Pathways to Power: Political Recruitment and Candidate Selection in Latin America. University Park, PA: The Pennsylvania State University Press, 2008. p. 41-75.

KLEIN, Cristian. $O$ desafio da reforma política: conseqüências dos sistemas eleitorais de listas aberta e fechada. Rio de Janeiro: Mauad X, 2007.

LIJPHART, Arend. Modelos de Democracias: desempenho e padrões de governo em 36 países. Rio de janeiro: Civilização Brasileira, 2003.

MAINWARING, Scott. Políticos, partidos e sistemas eleitorais - o Brasil numa perspectiva comparada. Novos Estudos, Cebrap, n. 29, p. 34-58, 1991.

NICOLAU, Jairo M.; SCHMITT, Rogério. A. Sistema eleitoral e sistema partidário. Lua Nova, Rio de Janeiro, v. 36, p. 129-147, 1995.

NICOLAU, Jairo M. O sistema eleitoral de lista aberta no Brasil. Dados - Revista de Ciências Sociais, Rio de Janeiro, v. 49 , n. 4, p. 689-720, 2006 a.

. Voto personalizado e reforma eleitoral no Brasil. In: SOARES, G.; RENNÓ, L. (Org.). Reforma política: lições da história recente. Rio de Janeiro, FGV, 2006b. p. 23-33.

RAE, Douglas. The political consequences of electoral laws. New Haven/London: Yale University Press, 1967.

ROJO, Raúl. E. El Sistema Político Argentino. In: ROJO, R. E.; TAVARES, J. A. (Org.). Instituições políticas comparadas dos países do Mercosul. 1. ed. Rio de Janeiro: FGV, 1998. p. 23-152.

SARTORI, G. Engenharia constitucional - como mudam as Constituições. Brasília. Ed. UnB, 1996.

SHUGART, Matthew S. Comparative Electoral Systems Research: The Maturation of a Field and New Challenges Ahead. In: GALLAGHER, Michael; MITCHELL, Paul (Ed.). The Politics of Electoral Systems. Oxford: Oxford University Press, 2005. p. 25-55.

TAVARES, José Antônio Giusti. O sistema político brasileiro. In: ROJO, R. E.; TAVARES, J. A. (Org.). Instituições políticas comparadas dos países do Mercosul. 1. ed. Rio de Janeiro: FGV, 1998. p. 153-348.

Sistemas eleitorais nas democracias contemporâneas. Teoria, instituições, estratégia. Rio de Janeiro: Relume Dumará, 1994. 